\title{
Kesesuaian Pengkajian Nyeri Pascaoperasi dan Tidak Lanjutnya dengan Standar Prosedur Operasional Asesmen Nyeri pada Pasien Pediatrik di RSUP Dr. Hasan Sadikin Bandung Tahun 2016
}

\author{
Iervan Churniawan, ${ }^{1}$ Doddy Tavianto, ${ }^{2}$ Suwarman ${ }^{2}$ \\ ${ }^{1}$ Instalasi Bedah dan Anestesi Rumah Sakit Tentara Tk. IV Sariningsih, Bandung, \\ ${ }^{2}$ Departemen Anestesiologi dan Terapi Intensif \\ Fakultas Kedokteran Universitas Padjadjaran/RSUP Dr. Hasan Sadikin Bandung
}

\begin{abstract}
Abstrak
Nyeri bukan hanya persepsi sensorik, tetapi juga emosi, kognitif, dan perubahan perilaku Pengkajian nyeri pada anak dinilai dengan berbagai sistem skoring. Rumah Sakit Umum Pusat Dr. Hasan Sadikin Bandung telah membuat Standar Prosedur Operasional untuk menilai nyeri di ruang perawatan. Penelitian bertujuan mengetahui kesesuaian pengkajian nyeri pascaoperasi dan tindak lanjutnya dengan SPO asesmen nyeri pada pasien pediatrik di Rumah Sakit Umum Pusat Dr. Hasan Sadikin Bandung pada tahun 2016. Penelitian menggunakan metode deskriptif observasional retrospektif terhadap 158 rekam medis pasien pediatrik yang dirawat pada tahun 2016. Penelitian dilakukan di RSUP Dr. Hasan Sadikin sejak Februari sampai dengan Maret 2018. Hasil penelitian mengungkapkan bahwa pengkajian nyeri sesuai SPO adalah 150 pasien $(94,9 \%)$, tidak sesuai SPO 8 pasien $(5,1 \%)$. Tindak lanjut pengkajian nyeri yang sesuai SPO adalah 138 pasien $(87,4 \%)$, tidak sesuai SPO 13 pasien $(8,2 \%)$, dan tidak dilakukan tindak lanjut 7 pasien $(4,4 \%)$. Evaluasi ulang setelah tindak lanjut pengkajian nyeri sesuai SPO adalah 130 pasien (82\%) dan tidak sesuai SPO 28 pasien (18\%). Simpulan penelitian ini bahwa pengkajian nyeri pascaoperasi dan tindak lanjutnya sebagian besar sudah sesuai dengan Standar Prosedur Operasional.
\end{abstract}

Kata kunci: Nyeri pascaoperasi, pediatrik, pengkajian nyeri

\section{Compliance of Postoperative Pain and Follow Up Assessment with Painful Assessment Standard Operating Procedures in Pediatric Patientsin Dr. Hasan Sadikin Bandung Year 2016}

\begin{abstract}
Pain does not only involve sensoric perception. It also involves emotional, cognitive, and behavioral changes. Pain assessment inf children is performed using various scoring systems. Dr. Hasan Sadikin General Hospital Bandung has developed Standard Operating Procedures to assess pain in treatment rooms. The objective of this study was to determine the compliance of postoperative pain assessment and its follow-up to the SOP on pediatric pain assessment in Dr. Hasan Sadikin General Hospital Bandung in 2016. This was a retrospective observational descriptive study on 158 medical records of pediatric patients who were treated during the period of 2016. The study was conducted from February to March 2018. It was revealed that pain assessment was assessed in compliance to the SOP in 150 patients (94.9\%) while the remaining 8 patients (5.1\%) were not assessed according to the SOP. The follow-up of pain assessment was performed in compliance with the SOP in 138 patients (87.4\%), Thirteen patients (8.2\%) were followed up using procedures that are not in compliance with the SOP while 7 patients (4.4\%) were not followed up at all. Reevaluation after pain assessment follow up was performed in compliance with the SOP in 130 patients (82\%) while the remaining 28 patients (18\%) were reevaluated without using the SOP. It is concluded that most postoperative pain assessments and their follow-up are conducted in compliance with the Standard Operating Procedures.
\end{abstract}

Key words: Postoperative pain, pediatric, pain assessment

Korespondensi: Iervan Churniawan, dr., SpAn, Instalasi Bedah dan Anestesi Rumah Sakit Tentara Tk. IV Sariningsih, Jl. R.E. Martadinata No.9, Citarum, Bandung Wetan, Kota Bandung, Jawa Barat 40115, Tlpn. (022) 4211650, Email iervantanjung@gmail.com 


\section{Pendahuluan}

Nyeri didefinisikan sebagai pengalaman sensoris dan emosional yang tidak menyenangkan terkait dengan kerusakan jaringan yang terjadi saat ini dan yang akan datang. ${ }^{1}$ Penyebab utama nyeri akut pada anak adalah prosedur pembedahan, trauma, dan penyakit akut. Nyeri pascaoperasi pada anak merupakan hal yang mengganggu kualitas hidup anak. Hal tersebut juga menjadi masalah utama pada pasien pediatrik setelah dilakukan prosedur operasi. Hingga saat ini penanganan nyeri pascaoperasi pada anak masih menjadi tantangan, dibuktikan masih banyak anak yang merasakan nyeri yang intens. ${ }^{2}$

Rasa sakit jika tidak ditangani dengan cepat dan efektif dapat menimbulkan gejala sisa secara fisik dan psikologis dalam jangka panjang. ${ }^{1}$ Tenaga kesehatan kadang meremehkan nyeri pada anak dan tidak menganggapnya sebagai prioritas termasuk pengkajian nyeri sebagai salah satu bagian penting dalam penatalaksanaan nyeri. ${ }^{1,3}$

Pengkajian nyeri secara rutin dan sistematis merupakan dasar tatalaksana nyeri yang efektif. Nyeri merupakan pengalaman subjektif sehingga nyeri yang disampaikan sendiri oleh tiap-tiap individu adalah metode yang lebih disarankan dalam pengkajian nyeri. Sayangnya, anak tidak dapat menyampaikan informasi tersebut dengan baik karena faktor usia atau status tumbuh kembangnya. Oleh karena itu, alat pengkajian nyeri observasional dan perilaku dapat digunakan sebagai alternatif pada kondisi tersebut. ${ }^{1,3}$

Pada dasarnya, tidak ada alat tunggal yang dapat digunakan untuk pengkajian nyeri pada semua anak atau semua kasus. Dalam pengkajian nyeri, penting untuk menilai, mencatat, dan mengevaluasi kembali rasa nyeri secara berkala dengan frekuensi pengulangan ditentukan sesuai dengan kebutuhan pasien., ${ }^{4,5}$

Rumah Sakit Umum Pusat Dr. Hasan Sadikin Bandung telah menetapkan standar prosedur operasional (SPO) berdasar atas Keputusan Direktur Utama RSUP Dr. Hasan Sadikin Bandung Nomor HK 02.04|8013/ 1040 II/2017 Tanggal: 12 Januari 2017 tentang panduan asesmen nyeri di RSUP Dr. Hasan Sadikin Bandung. Standar Prosedur Operasional tersebut dijadikan acuan bagi dokter dan perawat dalam melakukan penapisan atau evaluasi untuk mengidentifikasi rasa nyeri yang dirasakan pasien. Dalam praktiknya, telah disediakan formulir tentang asesmen dan monitoring lanjut di ruangan bagi dokter dan perawat dalam melakukan anamnesis tentang nyeri, termasuk lokasi, karakteristik, onset/durasi, frekuensi, kualitas, intensitas atau beratnya nyeri, dan faktor presipitasi. ${ }^{6}$

Dokter dan perawat melakukan evaluasi nyeri segera setelah masuk ruang pemeriksaan dengan menggunakan Numeric Rating Scale (NRS) dan Wong Baker Faces Pain Scale. Dokter melakukan penatalaksanaan nyeri sesuai dengan skala nyeri pasien dan perawat melakukan intervensi keperawatan sesuai dengan hasil evaluasi nyeri dan melakukan kolaborasi dengan Dokter Penanggung Jawab Pelayanan (DPJP). Perawat melakukan evaluasi ulang nyeri dengan interval 8 jam untuk nyeri ringan dan tidak nyeri, 2 jam untuk nyeri sedang, dan setiap jam untuk nyeri berat. ${ }^{6}$

Idealnya dengan SPO asesmen nyeri yang sudah dibuat dan dijalankan dengan baik maka kualitas penanganan nyeri dan tindak lanjut yang dilakukan dapat menurunkan angka morbiditas atau mortalitas nyeri yang tidak tertangani sehingga waktu perawatan pascaoperasi dapat lebih cepat. Namun, saat ini belum ada data yang menggambarkan tentang kualitas pengkajian nyeri pascaoperasi, tindak lanjut, dan evaluasi ulang nyeri pascaoperasi di ruang rawat inap di RSUP Dr. Hasan Sadikin sehingga perlu dilakukan penelitian tentang hal-hal tersebut.

Penelitian ini bertujuan mengetahui kesesuaian pengkajian nyeri pascaoperasi dan tindak lanjutnya dengan SPO asesmen nyeri pada pasien pediatrik di ruang perawatan RSUP Dr Hasan Sadikin.

\section{Subjek dan Metode}

Penelitian ini merupakan penelitian deskriptif observasional retrospektif. Penelitian dilakukan di RSUP Dr. Hasan Sadikin Bandung 
jalan Pasteur 38 pada bulan Februari sampai dengan Maret 2018. Subjek penelitian ini adalah pasien pediatrik pascaoperasi pada tahun 2016 dengan kriteria inklusi, yakni usia 2-18 tahun dan status American Society of Anesthesiologists (ASA) kelas I-III. Kriteria pengeluaran adalah tidak ada formulir asesmen nyeri dan monitoring lanjut dalam rekam medis serta tidak ada pengkajian nyeri pada lembar catatan keperawatan terintegrasi. Teknik pengambilan data melalui status rekam medis dengan jumlah minimum subjek yang diambil untuk penelitian deskriptif adalah $10 \%$ dari total populasi. Sampel diambil secara acak sistematis dari total 1.619 operasi dengan urutan $1,11,21,31$, dan seterusnya hingga tercapai jumlah sampel 162. Terdapat 4 subjek penelitian yang dikeluarkan dari penelitian ini.

Setelah mendapat persetujuan dari Komite Etik Penelitian Kesehatan Fakultas Kedokteran Universitas Padjadjaran/ RSUP Dr. Hasan Sadikin Bandung, peneliti melakukan pemeriksaan terhadap data rekam medis subjek penelitian sesuai dengan kriteria inklusi dan pengeluaran yang telah ditetapkan sebelumnya. Kemudian, dilakukan pengambilan data terkait teknik pengkajian nyeri pascaoperasi yang sesuai dan tidak sesuai dengan SPO, tindak lanjut hasil pengkajian nyeri pascaoperasi, dan evaluasi hasil tindak lanjut pengkajian nyeri pascaoperasi.

Data yang didapatkan kemudian diolah secara statistik. Analisis data bertujuan melihat gambaran proporsi tiap-tiap variabel yang akan disajikan secara deskriptif. Data kategorik dideskripsikan dengan distribusi frekuensi dan proporsi. Data yang diperoleh dicatat dalam formulir khusus, kemudian diolah melalui program statistical product and

\section{Tabel 2 Gambaran Pengkajian Nyeri} Pascaoperasi di Ruangan

\begin{tabular}{lcc}
\hline Pengkajian Nyeri & $\begin{array}{c}\text { Frekuensi } \\
\mathbf{n}\end{array}$ & $\begin{array}{c}\text { Persentase } \\
\text { \% }\end{array}$ \\
\hline Sesuai SPO & 150 & 94,9 \\
Tidak sesuai SPO & 8 & 5,1 \\
\hline
\end{tabular}

Keterangan: untuk data kategorik, data disajikan dengan jumlah atau frekuensi dan persentase
Tabel 1 Karakteristik Umum Subjek Penelitian

\begin{tabular}{lcc}
\hline $\begin{array}{c}\text { Karakteristik } \\
\text { Pasien }\end{array}$ & $\begin{array}{c}\text { Frekuensi } \\
\mathbf{n = 1 5 8}\end{array}$ & $\begin{array}{c}\text { Persentase } \\
\mathbf{( \% )}\end{array}$ \\
\hline Jenis kelamin & & \\
Pria & 111 & 70,3 \\
Wanita & 47 & 29,7 \\
Status ASA & & \\
1 & 116 & 73,4 \\
2 & 38 & 24,1 \\
3 & 4 & 2,5 \\
Usia (tahun) & & \\
Mean \pm SD & $8,97 \pm 6,038$ & \\
Median & 8,00 & \\
Range (min.-maks.) & $2,00-18,00$ \\
\hline
\end{tabular}

Keterangan: untuk data kategorik, data disajikan dengan jumlah atau frekuensi dan persentase. Datanumerikdisajikan dengan mean, median, standar deviasi, dan range (min.-maks.)

service solutions (SPSS) versi 24.0 for windows.

\section{Hasil}

Total data penelitian didapatkan sebanyak 162 sampel. Terdapat 4 data yang dikeluarkan pada penelitian ini karena ketiadaan lembar penilaian nyeri lanjutan dan penulisan pada lembar catatan terintegrasi.

Karakteristik umum pasien penelitian ditemukan laki-laki lebih banyak dibanding dengan perempuan, yaitu sebanyak 111 pasien atau 70,3\%, dengan status ASA paling banyak, yaitu kelas I sebanyak 116 pasien atau 73,4\%. Usia pasien rerata sebesar $8,97 \pm 6,038$ tahun (Tabel 1).

Pada penelitian ini didapatkan bahwa pengkajian nyeri pascaoperasi sesuai dengan SPO sebanyak 150 pasien atau 94,9\% (Tabel 2).

Tabel 3 Gambaran Tindak Lanjut Hasil Pengkajian Nyeri Pascaoperasi

\begin{tabular}{lc}
\hline \multicolumn{1}{c}{ Variabel } & $\begin{array}{c}\text { Skala (\%) } \\
\mathbf{n = 1 5 8}\end{array}$ \\
\hline Dilakukan sesuai SPO & $138(87,4 \%)$ \\
Tidak sesuai SPO & $13(8,2 \%)$ \\
Tidak dilakukan & $7(4,4 \%)$ \\
\hline
\end{tabular}

Keterangan: untuk data kategorik, data disajikan dengan jumlah atau frekuensi dan persentase 
Tabel 4 Gambaran Evaluasi Ulang Nyeri Pascaoperasi

\begin{tabular}{rcc}
\hline Nyeri & Dilakukan Sesuai SPO & Dilakukan Tidak Sesuai SPO \\
\hline Nyeri berat 1 jam & 1 & 0 \\
Nyeri sedang 2 jam & 4 & 4 \\
Nyeri ringan 8 jam & 125 & 24 \\
Total & $130(82 \%)$ & $28(18 \%)$ \\
\hline
\end{tabular}

Keterangan: untuk data kategorik, data disajikan dengan jumlah atau frekuensi dan persentase

Pada penelitian ini didapatkan gambaran tindak lanjut hasil pengkajian nyeri pascaoperasi pasien pediatrik di ruangan sebagian besar masih sesuai SPO, yaitu sebanyak 138 pasien atau 87,4\% (Tabel 3).

Evaluasi ulang nyeri pascaoperasi pasien pediatrik dilakukan setelah tindak lanjut dari pengkajian nyeri sebelumnya. Untuk nyeri berat dilakukan evaluasi ulang kembali setelah 1 jam. Nyeri sedang, dilakukan evaluasi ulang setelah 2 jam. Nyeri ringan dilakukan evaluasi ulang setelah 8 jam. Secara keseluruhan evaluasi ulang nyeri pascaoperasi telah dilakukan sesuai SPO pada 130 pasien atau 82\% (Tabel 4).

\section{Pembahasan}

Nyeri pascaoperasi yang parah pada pasien pediatrik berpotensi menimbulkan efek jangka panjang yang signifikan. Indikator yang menunjukkan rasa nyeri yang tidak terkontrol di antaranya perubahan tanda fisiologis seperti denyut jantung, laju pernapasan, tekanan darah, tekanan intrakranial, berkeringat, perubahan perilaku, penampilan, atau tingkat aktivitas anak. Nyeri akut yang tidak tertangani dengan baik tersebut dapat berkembang menjadi nyeri kronik. Oleh karena itu, manajemen nyeri merupakan prioritas internasional dalam bidang tata laksana pembedahan dan medical pada anak. ${ }^{2}$

Penelitian ini dilakukan pada 168 subjek yang diambil dari data rekam medis pasien pediatrik yang telah menjalani operasi di RSHS pada tahun 2016. Subjek penelitian ini terdiri atas 111 laki-laki dan 47 perempuan. Usia rerata pasien yang menjadi subjek dalam penelitian ini adalah 8 tahun. Subjek dengan status ASA I terdiri atas 116 anak, status ASA II terdiri atas 38 anak dan status ASA III sebanyak 4 anak.

Beberapa faktor yang dapat memengaruhi persepsi dan tingkah laku seseorang terhadap nyeri, yaitu: (1) jenis kelamin; (2) usia; (3) ras; (4) sosial budaya. Terkait dengan faktor jenis kelamin, beberapa penelitian menyatakan bahwa anak perempuan lebih sensitif dalam merasakan nyeri dibanding dengan anak laki-laki sehingga lebih tinggi prevalensi dan intensitas nyeri pascaoperasinya. Selain itu, hasil lainnya menunjukkan bahwa anak perempuan kurang dapat menoleransi nyeri atau mengekspresikan nyeri daripada anak laki-laki. Oleh karena itu, perawatan untuk anak dengan nyeri pascaoperasi harus mempertimbangkan aspek jenis kelamin karena dapat memengaruhi respons nyeri.

Suatu penelitian menunjukkan hubungan status fisik ASA dengan nyeri pascaoperasi yang tinggi. Penjelasan yang memungkinkan dari hal ini adalah pasien dengan status fisik ASA yang tinggi lebih cenderung menjadi sakit kronik dan memiliki nyeri kronik yang menetap. Penelitian sebelumnya pada pasien yang telah menjalani operasi abdomen elektif menyatakan hal berlawanan dengan penelitian lainnya, pasien ASA kelas I pada pembedahan ambulatori memiliki kejadian nyeri berat lebih tinggi daripada pasien yang memiliki ASA lebih tinggi. Akan tetapi, setelah diteliti ternyata hubungan antara variabel tersebut terbukti tidak signifikan. ${ }^{7-9}$

Pada penelitian ini didapatkan sebanyak 150 (94,9\%) pasien dilakukan pengkajian nyeri sesuai dengan SPO. Penelitian ini juga mendapatkan gambaran tindak lanjut pengkajian nyeri pascaoperasi yang sesuai 
dengan SPO sebanyak 138 pasien $(87,3 \%)$ dan didapatkan gambaran evaluasi ulang nyeri pascaoperasi yang dilakukan sesuai dengan SPO sebanyak 130 pasien (82\%). Standar Prosedur Operasional yang diterapkan di RSUP Dr. Hasan Sadikin digunakan untuk mempermudah dokter dan perawat dalam melakukan pengkajian nyeri, tindak lanjut pengkajian nyeri, dan evaluasi ulang nyeri pascaoperasi di ruang perawatan dengan target kepatuhan terhadap SPO adalah 100\% Namun, hasil penelitian ini didapatkan bahwa kepatuhan terhadap SPO tersebut tidak mencapai target yang diharapkan.

Pada peneltian ini tidak diteliti faktorfaktor yang menyebabkan target tersebut tidak tercapai. Penelitian sebelumnya menyatakan bahwa perawat tidak selalu menggunakan alat pengkajian nyeri yang tervalidasi berdasar atas usia untuk mengkaji tingkat nyeri pascaoperasi pada anak. ${ }^{10}$ Akibatnya penilaian status nyeri pada anak dapat tidak tepat. Kondisi tersebut dapat disebabkan oleh kurangnya pengetahuan tenaga kesehatan terhadap SPO yang sudah ada, serta pengalaman tenaga kesehatan dalam mengkaji nyeri pada anak sehingga dapat menyebabkan target kepatuhan tidak tercapai.

Penyebab lain yang mungkin berperanan adalah jumlah tenaga kesehatan yang bertugas tidak berimbang dengan jumlah pasien sehingga pengkajian pun akhirnya tidak dapat dilakukan tepat seperti yang disampaikan di dalam SPO. Seperti dinyatakan dalam penelitian di Thailand pada tahun 2014 bahwa beban kerja yang berat pada tenaga medis dapat menyebabkan kinerja mereka kurang optimal dalam melakukan pengkajian., ${ }^{5,10}$

Pencatatan yang tidak dilakukan secara rutin dan sistematis dapat juga menjadi faktor yang menyebabkan kepatuhan terhadap SPO tidak tercapai. Dinyatakan dalam penelitian dokumentasi bahwa penilaian nyeri harus dilakukan secara sistematis dan rutin. Faktanya, hal tersebut dilakukan secara tidak adekuat yang disebabkan oleh beberapa hal. Keterbatasan kemampuan perawat dalam mengkaji nyeri pada anak telah diidentifikasi sebagai kemungkinan hambatan untuk tata laksana nyeri yang optimal dan juga dapat menjelaskan kenapa anak sulit meyakinkan perawat bahwa mereka sedang merasakan nyeri. ${ }^{5,10}$

Kurang sosialisasi tentang SPO asesmen nyeri dan pelatihan terhadap tenaga kesehatan dalam mengkaji nyeri pada anak juga dapat menjadi faktor kurangnya kualitas kepatuhan pengkajian nyeri di ruangan. Hal ini sejalan dengan penelitian sebelumnya yang menyatakan bahwa 96\% perawat konsisten dalam melaksanakan pengkajian nyeri sesuai SPO, namun terkadang pengkajian tersebut tidak didokumentasikan oleh tenaga medis. Hal ini dapat mengindikasikan bahwa edukasi pada tenaga medis merupakan hal penting agar pengkajian dan tindak lanjut nyeri pada pasien dapat meningkat keberhasilannya.,7

Rumah sakit di luar negeri memiliki sekelompok tenaga medis khusus untuk menangani nyeri pascaoperasi pada pasien. Hal tersebut membuat proses penilaian dan manajemen nyeri pascaoperasi pada pasien dapat dilakukan dengan lebih intensif dan spesifik sehingga pada akhirnya kepuasan pasien dan keluarga terhadap manajemen nyeri pun meningkat. ${ }^{7}$ Hal tersebut belum dapat terwujud di sini.

Dampak yang dapat terjadi akibat dari kualitas pengkajian yang kurang baik adalah peningkatan angka morbiditas dan mortalitas akibat nyeri yang tidak tertangani, serta waktu tinggal perawatan pascaoperasi yang memanjang. ${ }^{1,5}$

\section{Simpulan}

Pada penelitian ini didapatkan hasil bahwa pengkajian nyeri pascaoperasi, tindak lanjut, dan evaluasi ulang pengkajian nyeri pascaoperasi pada pasien pediatrik di ruang rawat inap RSUP Dr. Hasan Sadikin Bandung sebagian besar sudah sesuai dengan SPO asesmen nyeri, tetapi belum mencapai target 100\%. Diperlukan edukasi, pelatihan, dan sosialisasi SPO terhadap tenaga kesehatan secara berkala, penelitian lanjutan berdasar atas bukti sesuai dengan faktor-faktor yang membuat target kepatuhan tidak tercapai. 


\section{Daftar Pustaka}

1. Wong C, Lau E, Palozzi L, Campbell F. Pain management in children: Part 1- pain assessment tools and a brief review of nonpharmacological and pharmacological treatment options. Can Pharm J. 2012;145(5):222-7.

2. Brasher C, Gafsous B, Dugue S, Thiollier A, Kinderf J, Nivoche Y, dkk. Postoperative pain management in children and infants: an update. Pediatr Drugs. 2014;16:12940.

3. Nair S, Neil MJE. Paediatric pain: physiology, assessment and pharmacology. ATOTW. 2013;289:1-10.

4. Cohen LL, Lemanek K, Blount RL, Dahlquist LM, Lim CS, Palermo TM, dkk. Evidencebased assessment of pediatric pain. J Pediatr Psychol. 2008;33(9):939-55.

5. Thienthong S, Sriraj W, Siripul P, Finley A, Boonyawattanangkool K, Kasetwetin S. A survey of postoperative pediatric pain management among seven hospitals in northeastern Thailand. Anaesth Pain Intens Care. 2014;18(1):59-71.

6. Sadikin RDH. Asesmen nyeri. Bandung: RSUP Dr. Hasan Sadikin; 2015.

7. Moura L, Oliveira ACD, Pereira GA, LV P. Postoperative pain in children: a gender approach. Rev Esc Enferm USP. 2011;45(1):831-6.

8. Kozlowski LJ, Kost-Byerly S, Colantuoni E, Thompson CB, Vasquenza KJ, Rothman SK, dkk. Pain prevalence, intensity, assessment and management in a hospitalized pediatric population. Pain Management Nurs. 2014;15(1):22-35.

9. Kinjo S, Sands LP, Lim E, Paul S, Leung JM. Prediction of postoperative pain using path analysis in older patients. J Anesth. 2012;26(1):1-8.

10. Panjganj D, Bevan's A. Children's nurses' post-operative pain assessment practices. Nurs People Young Child. 2016;28(5):2933. 